\title{
Facebook influences you more than me: The perceived impact of social media effects among young Facebook users
}

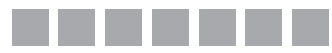 \\ Nicoleta Corbu \\ Oana Ştefăniță \\ Raluca Buturoiu \\ NATIONAL UNIVERSITY OF POLITICAL STUDIES AND PUBLIC ADMINISTRATION, ROMANIA \\ DOI: 10.19195/1899-5101.10.2(19).6
}

\begin{abstract}
The popularity and prevalent use of Facebook among young people are common preoccupations for communication researchers. They focus on unveiling people's motivations, usage behaviour, and gratifications offered by this communication medium. However, little attention has been invested in examining how young people perceive this new type of media consumption and its effects on themselves as compared to others. Drawing on Davison's (1983) third-person effect hypothesis, this research paper investigates the (a) differences in estimated Facebook effects on self versus others, (b) association between the desirability of the message (anti-social versus pro-social) and estimated Facebook effects on self versus others, and (c) association between the type of the message and estimated Facebook effects on self versus others. These relationships are studied with reference to the behavioural component of the third-person effect. Results confirm that Facebook might influence the magnitude and direction of the perceptual gap of media effects.
\end{abstract}

KEYWORDS: Third-person effect, social media, behavioural component of the TPE, message desirability, message type.

\section{INTRODUCTION}

The current popularity and usage of social networking sites (especially Facebook) are high among young people. Thus, it is not surprising that this popular social networking platform has attracted the interest of scholars from diverse areas including communication, psychology, and advertising. Recent studies were mainly intended to cover topics such as people's motivations for using and engaging on the platform, 
people's usage behaviour, their attitude towards privacy, the gratifications related to the use of Facebook as a communication tool, and the benefits of using Facebook as a social learning tool. However, little attention has been invested in the study of perceived effects of social networking sites (and, particularly, Facebook) on users themselves versus others (see for instance Tsay-Vogel, 2015).

Research designed to reveal the perceived influence of media is not so recent. It has been previously applied to topics including politics, violence, pornography, or advertising. Nevertheless, exploring people's perceptions of media influence in the context of the continuous development of newer media outlets is still an under-explored domain. Specifically, due to the emergence and development of technology and information tools, it is a must to take into consideration how people perceive the impact of these newer mediums of communication and information, both on themselves and on others. In this context, our interest is to explore how young people (by far, the most avid users of social networking sites, according to statistics) perceive the way Facebook influences themselves or others in what regards taking action on various issues.

Based on the theoretical framework of Davison's (1983) third-person effect (TPE), this paper aims at uncovering if newer media outlets elicit similar effects as traditional media, and under which circumstances these effects occur. More specifically, the aim of this article is to give answers to the following question: Are young people more inclined to perceive themselves or others as being more influenced by the media (i.e., Facebook)? Is the perceived intensity of Facebook influence mediated by other variables (i.e., message desirability and personal relevance of the topic)? Providing answers to these questions might be helpful not only for communication scholars interested in studying mass-media effects, but also for policy and decision makers who would like to take documented and empirically-based decisions.

\section{THIRD-PERSON EFFECT — PERCEPTIONS AND BEHAVIOURS}

Third-person effect states that people tend to expect others to be more influenced by media messages than they are. Davison (1983) proposed the TPE hypothesis, namely that people overestimate the impact of media on others, and the way their attitudes or behaviours might be affected. Since then, media scholars have reported solid empirical evidence to support the TPE (e.g., Chapin, 2002, 2013; Cohen \& Davis, 1991; David \& Johnson, 1998; Davison, 1996; Duck et al., 1999; Gunther, 1991; Hoffner \& Buchanan, 2002; Huh et al., 2004; McLeod et al., 2001; Bryant et al., 2000; Perloff, 1993, 1999, 2002; Price \& Tewksbury, 1998; Sun et al., 2008), emphasizing that the more negative or controversial the messages are, the stronger the perceived influence on others. 
The TPE contains a perceptual and a behavioural component. The perceptual dimension refers to people's belief that exposure to media messages would have a greater impact on others than on themselves. Studies on the perceptual bias identified a stronger occurrence of the effect when the messages are perceived as undesirable and when the issue is personally important (Perloff, 1993). The opposite effect is called first-person perception and appears in connection with positive, desirable messages whose influence is perceived as casting a good light on those who are affected by the content (Andsager \& White, 2007). Media effects are also correlated with a second person effect, meaning the self as well as others are affected (Neuwirth et al., 2002).

The TPE is determined by a process called the fundamental attribution error (McLeod et al., 2001). This process refers to people who attribute the negative consequences concerning themselves on situational aspects and on individual characteristics when the focus is on others. People are in need of maintaining a positive image about themselves, a process of ego enhancement (Brown, 1986; Perloff, 1989), or selfserving bias and the need to feel in control (Gunther, 1995). Another circumstance that increases the effect is when another person or group is perceived as being part of the audience of the message in question, thus being more likely to consume and be influenced by a message (Eveland et al., 1999). However, when people feel they are part of the target of a message but they are not influenced by it, they assume the others are more influenced by that particular media content, thus favouring the TPE (White \& Dillon, 2000).

While the perceptual component refers to the discrepancy in assessing the influence of media for self and others, the behavioural component proposes that people will act to censor negative media messages associated with a third-person perception bias (Davison, 1996; Perloff, 2002; Salwen, 1998). Previous studies indicated that the reaction of individuals in terms of behaviour towards media content is influenced by their perception of how messages might affect others and what others will do as a consequence of being influenced by those messages (Jensen \& Hurley, 2005; Tewksbury et al., 2004).

Therefore, if people assume a certain influence of a message on the public, they will adapt their behaviour to correspond to this assumption, especially through manifesting support for restricting the media content (Gunther \& Storey, 2003; Hoffner \& Buchanan, 2002; McLeod et al., 2001; Neuwirth et al., 2002). Davison (1983) noted that regarding the censorship of the media, the censors do not admit being influenced by a negative content, nor their in-group, but the other people in general need these protective measures. Therefore, if people overestimate the influence of media on others, they will take action to restrict the potentially harmful content (Golan \& Banning, 2008). Yet, as users of certain content, we are less likely to evaluate its effects as harmful to others, so the perception bias and the behavioural component will vary from person to person. Nonetheless, there is insufficient research to affirm that the perception bias will determine real life consequences in terms of behaviour (Gunther \& Storey, 2003; Perloff, 1999). The studies conducted in this area measure the 
willingness to censor controversial content. Researchers found support for willingness to exert control in relation with violent or misogynistic rap music, pornography, violence, political communication, or advertising of controversial services (e.g., Gunther, 1995; McLeod et al., 1997; Rojas et al., 1996; Salwen, 1998). Emotions may be a mediator between TPP and the behavioural component, as emotions are triggering certain outcomes of a perceived influence. For example, anxiety or anger may lead to information seeking, to active participation, especially in politics, or willingness to ban harmful content (Huddy et al., 2007; Kim, 2016; Kepplinger, 2008). While most research regarding the behavioural dimension examined the support for message restrictions, other behaviours are possible so further research is needed to support the TPE (Wu \& Koo, 2001).

Overall, studies have indicated that individuals tend to overestimate media effects on others, but underestimate them on themselves. The perceptual component of this effect emphasizes the gap in estimating media effects on self and others, while the behavioural component deals with how people act based on their assumptions. Both components are dependent on the valence of media content.

\section{PREDICTORS OF THE THIRD-PERSON EFFECT}

Previous studies identified a series of moderators that influence the magnitude of the TPE. For example, social distance might be an important predictor, meaning that the relationship of the target with the perceiver, if the perceiver is part of the group in question or not, will determine variations of the TPE (Reid \& Hogg, 2005). The effect increases due to the social distance (Meirick, 2005). The concept of reference groups and the resemblance or difference from the self, influence the perceived effects on others. The more different and distant the group in question, the greater the effect (Davison, 1983; White, 1997). The higher impact is correlated with public opinion in a broad sense (Cohen et al., 1988). Self might also be involved in the TPE as those with high self-esteem proved to have an increased third-person perceptual bias (David \& Johnson, 1998). People have a set of positive illusions about themselves, their traits, and their abilities to maintain selfesteem. In this context, self-enhancement is an important aspect in determining the TPE. Furthermore, cross-cultural studies found that the TPE was larger in individualistic rather than collectivistic cultures (Lee \& Tamborini, 2005). Still, in the case of desirable content, being influenced by a message might mean to be open-minded, smart, responsible, in which case the effect will turn into a first person effect, the self and the in-group members being more influenced than others, as this will cast a positive image on the influenced ones (Duck et al., 1995). First-person effects have been found for prosocial content such as public service announcements, safety, or responsible behaviours (Meirick, 2004; White \& Dillon, 2000). 
Negative and controversial content such as pornography, misogynistic lyrics, gambling, tobacco and alcohol advertisements, violence, political advertising, magazine advertisements, and video gaming are generally found to determine an increase in the TPE, being perceived as socially undesirable messages (Banning, 2001; Eveland et al., 1999; Golan, 2002; Rojas et al., 1996; Zhong, 2009). There is robust support for the connection between undesirable media messages and TPE (Bryant, Salwen \& Dupagne, 2000).

TPE is understudied in relation with Facebook and the perceived influence of this social platform on others, although the psychological mechanisms might support the same pattern of effects in terms of Facebook usage as well (Tsay-Vogel, 2015). If the accessibility of information and control over the target audience for a message are higher, Facebook users might overestimate the effects on others (Mangold \& Faulds, 2009). Moreover, besides the level of desirability of media content that triggers variation in TPE, it is possible that the perceived desirability of the medium has the same influence. Thus, if the perceivers estimate that Facebook has negative effects on users, the TPE should be greater, and smaller if Facebook is seen as having a positive influence (Tsay-Vogel, 2015).

Overall, the TPE predicts that others are more influenced by media messages, and a series of moderators such as social distance, audience vulnerability, likelihood of exposure, knowledge, self-esteem, type of content, and level of desirability might determine variations of the effect. The strongest influence is found in relation to negative media content. However, insufficient research has been carried out for new media or with a focus on the behavioural component and, therefore, the present study addresses these two dimensions and further explores the third-person effects.

\section{STUDY GOALS AND HYPOTHESES}

In this study, we investigate the TPE in the context of social media, focusing on the behavioural component. Specifically, we seek to explore the differences between estimated Facebook effects on self vs. others (H1), while at the same time looking into the mediated effects of socially desirable messages $(\mathrm{H} 2)$ and the personal relevance (the degree of importance of the topic) of the content of Facebook messages (H3).

H1. Young people generally believe that they are less influenced by social media messages than others in regards to taking action on various issues.

$\mathrm{H} 2$. The intensity of the TPE is influenced by the social desirability of the message. Specifically: Young people believe they are less influenced than others by social media messages to a higher degree when the message refers to a socially undesirable topic than when the message refers to a socially desirable topic.

H3. The intensity of the TPE is influenced by the personal interest people hold for the message. In other words: Young people believe they are less influenced 
than others by social media messages to a higher degree when the message refers to a personally irrelevant topic than when the message refers to personally relevant one.

\section{METHOD}

\section{Sample}

Previous studies showed that students, if not entirely homogenous in terms of socio-demographics, could be a fairly good sample of experiment subjects in various topics research (Nelson et al., 1997). In this study we used a sample of undergraduate $(\mathrm{N}=599)$ and graduate $(\mathrm{N}=89)$ students of a Romanian social-sciences university $(\mathrm{N}=688)$, in order to test the influence of Facebook messages on young people's behaviour. The sample consists of people aged 17 to 39 years old $(\mathrm{M}=$ $20.63, \mathrm{SD}=2.37$ ).

\section{Design}

To assess the influence of social desirability and personal relevance of social media messages we used a $2 \times 2$ experimental design, plus a control group. The 688 students were randomly assigned to one of the five conditions, represented by four types of stimuli, and the control group: socially desirable personally relevant topic $(\mathrm{N}=139)$, undesirable personally relevant topic $(\mathrm{N}=140)$, desirable personally irrelevant topic $(\mathrm{N}=137)$ undesirable personally irrelevant topic $(\mathrm{N}=135)$, and the control group (137).

\section{Stimuli}

For the socially desirable, personally relevant message, we used the topic of making the universities safer for students from the point of view of fire protection. This is a highly sensitive topic among young Romanians, after an incident that killed more than 60 young people at a concert because of the lack of fire protection at the location. This was considered a national tragedy and elicited large public debates about fireproofing of public institutions. Dropping the admission exams in state universities was the socially undesirable, personally relevant topic, in the context of the general debate about the continuously degrading state of higher education in Romania. The pension system was chosen as a topic lacking personal relevance, with regards to the poor population (desirable component) and the members of the Romanian Parliament (undesirable component). Pensions of the members of the Romanian Parliament have been the subject of intense debate in recent years in Romania. The level of corruption of Romanian politicians makes the topic socially undesirable, since common people tend to believe that politicians always raise their own pensions, and not those of poor people. However, students in general do not 
find this particular topic of interest (because of their young age). The stimuli were short written stories, allegedly viral on the Facebook network "these days", constructed as proposals of changing the current legislation. Both the stimuli and the questionnaire were pretested on a sample of 26 students prior to the experiment.

\section{Measures}

The questionnaire used in the experiment contained both pre-test and post-test scales, which allowed for in-depth analysis of the results. The dependent variables were created using pairs of questions testing opinions, attitudes and behaviours of "me" vs. "others". In this study we focus on the behaviour component, measured on a 7-point Likert scale asking about the willingness to participate in a public protest supporting the legislation proposal presented in the stimuli. The intensity of the TPE was measured through the difference between the mean of the "others" and "me" variables, therefore a positive value showing a third-person effect.

\section{FINDINGS}

Generally speaking, in the control group, young people believe that others are much more influenced $(\mathrm{M}=5.49, \mathrm{SD}=1.26)$ than themselves $(\mathrm{M}=3.85, \mathrm{SD}=1.61)$ by the articles read on Facebook. Equally, when generally asked about the Facebook influence, even people exposed to the stimuli respond in about the same manner. Specifically, they believe that others are more influenced $(M=5.46, S D=1.18)$ than themselves $(\mathrm{M}=3.88, \mathrm{SD}=1.54)$. There is no significant difference between the control group and all other groups in terms of the intensity of the TPE ( $t$ test not significant). Not only are people generally convinced that they are much less influenced by FB than others, but they position themselves below the mean of the scale, in the "not much influenced" range, while placing others in the "much influenced" area of the scale. The classic TPE seems to stand in the social media domain, regardless of the personal characteristics of the people or of the stimuli that they might be exposed to, at one particular moment ( $\mathrm{H} 1$ confirmed).

As far as the behaviour component of the TPE is concerned, the data show a great mean difference between "self" $(M=2.62, S D=1.78)$ vs. "others" $(M=4.06$, $\mathrm{SD}=4.06, \mathrm{SD}=1.53$ ), with people estimating others at about the mean of the scale, and themselves in the area of very low influence.

The differences between the groups are small. Namely, young people exposed to the socially desirable story as compared to those exposed to the socially undesirable story have the same behaviour. Generally speaking, the intensity of the TPE remains the same, with the difference that people estimate that both themselves and others would be a little more influenced by the socially desirable topic. Nevertheless, the differences are negligible (Table 1) (H2 invalidated). 
Nicoleta Corbu, Oana Ştefăniţă, Raluca Buturoiu

Table 1. TPE based on the desirability of the topic

\begin{tabular}{|l|c|c|c|c|}
\hline \multicolumn{2}{|c|}{ Social desirability of the topic } & Behaviour of self & $\begin{array}{c}\text { Behaviour of } \\
\text { others }\end{array}$ & Intensity of TPE \\
\hline \multirow{3}{*}{ Socially undesirable } & Mean & 2.31 & 3.81 & 1.50 \\
\cline { 2 - 5 } & N & 272 & 272 & 272 \\
\cline { 2 - 5 } & Std. Deviation & 1.65 & 1.56 & 1.84 \\
\hline \multirow{3}{*}{ Socially desirable } & Mean & 2.93 & 4.31 & 1.38 \\
\cline { 2 - 5 } & N & 275 & 275 & 275 \\
\cline { 2 - 5 } & Std. Deviation & 1.85 & 1.45 & 1.81 \\
\hline
\end{tabular}

Source: Authors.

Contrary to expectations, no first person effect was present at all in the case of the socially desirable topic. At the same time, the mean difference between people willing to participate in a protest supporting a change of legislation proposal in the case of the desirable and undesirable topics is not significant, either for "me" or for "others" (t test is not significant). Nonetheless, the social desirable topics elicit a higher willingness of people to get involved in a protest than a socially undesirable one, but at the same time, people also estimate that others would get more involved in a protest supporting a legislation proposal in the case of the socially desirable topic. We believe that the first person effect was absent, due to the fact that the socially desirable topic was not appealing enough to make them interested in taking action. The lower means for both socially desirable and undesirable topics argue for a low level of involvement in both cases. We will further address this in the Limitations section.

However, the nature of the topic and its relevance to the subjects questioned showed significant differences in regards to the intensity of the behaviour component of the TPE $(t=2.713, \mathrm{df}=545, \mathrm{p}<.01)$ ( H3 confirmed).

Table 2. TPE based on the personal relevance of the topic

\begin{tabular}{|l|c|c|c|c|}
\hline \multicolumn{2}{|c|}{ Personal relevance of the topic } & Behaviour of self & $\begin{array}{c}\text { Behaviour of } \\
\text { others }\end{array}$ & Intensity of TPE \\
\hline \multirow{3}{*}{ Personally irrelevant } & Mean & 2.21 & 3.87 & 1.66 \\
\cline { 2 - 5 } & $\mathrm{N}$ & 269 & 269 & 269 \\
\cline { 2 - 5 } & Std. Deviation & 1.52 & 1.59 & 1.70 \\
\hline \multirow{3}{*}{ Personally relevant } & Mean & 3.02 & 4.24 & 1.22 \\
\cline { 2 - 5 } & $\mathrm{N}$ & 278 & 278 & 278 \\
\cline { 2 - 5 } & Std. Deviation & 1.92 & 1.44 & 1.91 \\
\hline
\end{tabular}

Source: Authors. 
The personal relevance of the topic seems to matter more in eliciting a third person effect. However, when analysing the means of people's estimates of selves and others' behaviours, only in the case of others' behaviour for personally relevant topic people estimate the willingness to participate in a protest above the mean of the 7-point scale $(\mathrm{M}=4.24)$.

Taking into consideration the combination of both relevance of the subject and social desirability, the differences regarding the intensity of the TPE at the behaviour level are significant for the "personally relevant, socially desirable" topic (post hoc ANOVA Tukey test differences significant, $\mathrm{F}=6.988$, $\mathrm{df}=546, \mathrm{p}<.01$ ) (see Table 3 for the intensity of the TPE measures - general means of difference in behaviour "me" vs. "others").

Table 3. General means of the intensity of the TPE: difference in behaviour "me" vs. "others" based on the nature of the topic

\begin{tabular}{|l|c|c|c|}
\hline \multicolumn{1}{|c|}{ Type of topic } & N & Mean & Std. Deviation \\
\hline Personally relevant desirable & 138 & .90 & 1.710 \\
\hline Personally irrelevant undesirable & 132 & 1.42 & 1.592 \\
\hline Personally relevant undesirable & 140 & 1.55 & 2.047 \\
\hline Personally irrelevant desirable & 137 & 1.87 & 1.777 \\
\hline
\end{tabular}

Source: Authors.

The intensity of the third person effect was much higher for the personally relevant, desirable topics, compared to personally irrelevant, desirable topics, which argues for a minimum (if existent at all) effect of the social desirability of the topic.

To sum up, we confirmed a general TPE elicited by the Facebook messages among young people. At the same time, the social desirability of the message does not seem to play a great role in changing the direction or the intensity of the effect, while the personal relevance of the topic seems to decrease the intensity of the TPE at the behaviour level.

\section{DISCUSSION}

The main goal of this research was to investigate the TPE and its prevalence among young people in the context of social media. With a specific focus on the behavioural component of the TPE, our research was intended to discover and examine the differences in estimated Facebook effects on self versus others regarding the readiness to take action on various issues (i.e., focusing more on the behavioural component and less on the perceptual one); the relationship between the TPE and the social desirability of the message, and the relationship between the TPE and the personal importance attached to the message. The data from our research provide significant support for 
TPE in the context of social media, with rather similar estimated effects compared with those elicited by traditional media outlets (see for instance Golan \& Banning, 2008; Johansson, 2002; Price et al., 1997; Tsfati \& Cohen, 2004).

In general, our findings are consistent with Davison's (1983) TPE hypothesis, initially designed with reference to traditional mediums of communication. Furthermore, when applied to newer communication mediums, the results follow the same direction in the sense that when asked about taking action (i.e., about the willingness and readiness to participate in a public protest supporting the legislation proposal presented in the stimulus material), young Facebook users tend to report a stronger influence of Facebook on others than on themselves, irrespective of any other moderator variables (i.e., the social desirability of the message or the personal importance attached to the message content). These results are in line with other recent studies, revealing the "discrepancy that lies in the estimated use and effects of Facebook between self and others" (Tsay-Vogel, 2015, p. 11).

The first hypothesis stated that young people generally believe that others are more influenced by social media messages as compared to themselves with reference to taking action on various issues. This hypothesis proved to be true, meaning that young people perceive that Facebook is influencing others more than themselves. Despite the general pattern, which could be easily criticized, the results at this level might be interpreted as valuable from at least two connected points of view. First, we noticed that, despite its fashionable character, popularity, and heavy usage especially among young people, Facebook is a tool whose influence tends to be neglected. Paradoxically, although they spend much time using Facebook for various activities, young people tend to place themselves out of its influence and consider others much more vulnerable. One possible explanation for this result might be linked to what scholars refer to as an "ego enhancement" cognitive strategy. Specifically, irrespective of media form and content, people have a tendency towards making "self-serving judgments in order to maintain their self-esteem and sense of control" (Price et al., 1997, p. 527). This means that perceiving others as being more vulnerable and even more negatively affected by media is motivated by people's need for ego enhancement (Boyle et al., 2008) and that this holds true in social media contexts as well. In other words, the perceived TPE could be much more related to self-positioning oneself in the best light rather than thinking badly of other people.

Another important aspect to consider in relation to our results confirming the prevalence of TPE among young people with reference to social media contexts is linked to Facebook's rather controversial character. Although it encompasses a range of virtually good things, among which the possibility to keep in touch with people from distant places and the almost instant communication facilities are the most mentioned, Facebook activities are sometimes regarded as time-consuming and counter-productive. Therefore, somebody's acknowledgement of being influenced by Facebook news in order to take action on various topics could mean automatic damage to his or her public image. 
Besides the similarities with previous studies, there is at least one main difference. Namely, young people from our study did not "overestimate the influence that mass communications have on attitudes and behaviour of others" (Davison, 1983, p. 3). Instead, our findings suggest that the significant difference between self and others comes from people's tendency towards "largely underestimating media effects on themselves" (Golan \& Banning, 2008, p. 209). As noted earlier, this means that the TPE could have its origins in people's need to self-position in a "safe place" or best light and preserve a high level of self-esteem rather than in any badly intentioned behaviour towards others.

The second and the third hypotheses from our study referred to the intensity of the TPE. The second hypothesis focused on the social desirability of the message and the way it might influence the intensity of the TPE effect, in the sense that a socially desirable story could drive people to consider that they are more influenced than others (i.e., being the sign for the presence of reverse TPE or the so-called first person effect). This second hypothesis was invalidated, since the intensity of the TPE remains the same in the case of both socially desirable and undesirable topics. These results contradict our expectations, mainly coming from previous research studies (i.e., Gunther \& Mundy, 1993; Price et al., 1997), which stated that the pro-social nature of a message aimed directly at a socially desirable outcome might lead individuals to find themselves more influenced than others (i.e., pro-social messages lead to higher FPE), whereas when an intended media stimulus is perceived to lead to socially undesirable behaviours, it might determine people to rate others as more vulnerable (i.e., antisocial messages lead to higher TPE). One possible explanation for these results could be linked to the fact that there is such a generalized attitude towards placing oneself in the best light possible that, irrespective of its social desirability, individuals believe that others are more exposed and thus, more influenced, and more vulnerable to this relatively new medium, subject to yet unclear valence evaluation. This holds particularly true in social media contexts, where individuals are exposed to such a tremendous amount of information and news that it is fairly hard to clearly filter the socially desirable topics from the undesirable ones.

The personal relevance of the topic and its influence on the intensity of the TPE was tested in the third hypothesis, in the sense that a personally irrelevant topic could lead to higher levels of TPE. The hypothesis was confirmed, suggesting that a personally relevant story leads people to admit that, not only are the others influenced, but themselves as well. With reference to the connected influence of both the social desirability of the topic and its personal relevance, findings prove that a socially desirable topic regarded as personally relevant, compared with a socially desirable topic regarded as personally irrelevant, could lower the TPE. In other words, in line with other recent research studies (Schweisberger et al., 2014), our findings show that, irrespective of its social desirability, the more relevant the topic, the lower the TPE among young Facebook users. 
The above-mentioned findings could be explained with reference to the social distance corollary, suggesting that the nature and intensity of the TPE depends "on the identity of the comparison others" (Tsay-Vogel, 2015, p. 12). Particularly, TPE diminishes when the social distance between self and other decreases, whereas TPE increases when others increase in generality (also see McLeod et al., 1997). Thus, applying these possible correlations to Facebook, there is a high possibility that, when young people were asked to evaluate the attitudes and behaviours of "others", they could have evaluated people in their respective social networks, including their close friends. Therefore, in this case, the psychological distance between self and others is insignificant to the extent that it leads to biased or limited perceptions. If users are evaluating the impact of Facebook on their own friends, the motivation to preserve their self-esteem and to position themselves in the best light possible might be very high, and, thus, users might be less likely to report their own friends as being susceptible to social media influence. Reporting their own friends as being influenced by Facebook, implicitly means acknowledging self-influence. Thus, due to this flimsy delineation between self and others in the context of the TPE, researchers should take into account that it is necessary to point out the conceptual and methodological challenges involved when defining and evaluation "hypothetical others" (Tsay-Vogel, 2015, p. 12).

\section{LIMITATIONS AND FURTHER RESEARCH}

There are some limitations in this research. The first one is the lack of extensive studies referring to the TPE in the context of social media outlets. The few existing studies with reference to this topic could not allow for a more consistent methodological design and for empirically-based comparisons. Another limitation is related to the measures for the perceived impact of Facebook, which could be biased due to the wording and the manner of presenting the statements. As documented in other studies, it is highly important to take into account the way of phrasing a statement when measuring perceptions, attitudes and behaviours. For example, as Tsay-Vogel (2015, p. 13) suggests, it is possible that people could be more willing to report effects of Facebook on themselves (i.e., first person effect could be higher) if statements were phrased in the active voice rather than in the passive voice.

The intensity of the stimuli is arguably an important limit, especially for the social desirability dimension. Even though there was a pre-test of the stimuli in the sense of general appreciation of the social desirability of the topics, we believe that stronger negative connotations of the socially undesirable content might nuance the results.

Furthermore, as briefly explained earlier, drawing from the social distance corollary, the lack of a clear definition of "others" could be another limitation of the present research. Future research studies should take into consideration the fact that it is critically important to define "others", since the delineation between "generalized" (people in general) and "specialized" (close friends) others could have a serious impact on the magnitude and intensity of the TPE. It is important to admit 
that these delineations are relevant mainly for such homogenous samples, as was the case in our study.

Finally, the convenience sample limits the generalisability of the results, especially due to the relative homogeneity of the subjects in the experiment in terms of age and education.

\section{CONCLUSIONS}

Our research offers support for Davison's (1983) TPE hypothesis, in a different cultural context. Thus, TPE is a generalized effect that consistently applies to newer media outlets, namely Facebook. In particular, our main findings show that TPE exists among young Romanian users of Facebook and that the intensity of TPE varies according to the personal relevance of the social media topic to which people are exposed. Facebook messages perceived as personally relevant lead to lower levels of TPE as compared to personally irrelevant messages; the social desirability of the messages does not seem to have a role, neither with reference to themselves, nor to other people.

These findings could be used as starting points for future research studies referring to either Facebook in particular or to other, even newer mediums of communication. Due to the quick evolution of social networking sites and to the fact that research on the medium must be continually updated, since even the slightest "change in format may have significant ramifications for social media research" (Schweisberger et al., 2014, p. 411), the applicability and functioning of TPE, as an already classic theory of media effects studied with reference to new mediums of communication, might be a sign that the theory is still valid and could be used by both scholars assessing mass media effects and policymakers in the broad areas of communication, media and advertising.

\section{REFERENCES}

Andsager, J.L., White, H.A. (2007). Self versus others: Media, messages, and the third-person effect. Mahwah, NJ: Lawrence Erlbaum.

Banning, S.A. (2001). Do you see what I see? Third-person effects on public communication through self-esteem, social stigma, and product use. Mass Communication and Society, 4(2), pp. 127-147.

Boyle, M.P., McLeod, D.M., Rojas, H. (2008). The Role of Ego Enhancement and Perceived Message Exposure in Third-Person Judgments Concerning Violent Video Games. American Behavioral Scientist, 52(2), pp. 165-185.

Brown, J.D. (1986). Evaluations of self and others: Self-enhancement biases in social judgments. Social Cognition, 4, pp. 353-376.

Bryant, P., Salwen, M.B., Dupagne, M. (2000). The third-person effect: A meta-analysis of the perceptual hypothesis. Mass Communication \& Society, 3, pp. 57-85.

Chapin, J. (2002). Third-person perception and school violence. Communication Research Reports, 19 , pp. 216-225.

Chapin, J. (2013). I Know You Are, but What Am I? Adolescents' Third-Person Perception Regarding Dating Violence. The Journal of Educational Research, 106(5), pp. 393-398. 
Cohen, J., Davis, R. (1991). Third-person effects and the differential impact in negative political advertising. Journalism Quarterly, 68, pp. 680-688.

Cohen, J., Mutz, D., Price, V., Gunther, A.C. (1988). Perceived impact of defamation: An experiment on third-person effects. Public Opinion Quarterly, 52, pp. 161-173.

David, P., Johnson, M.A. (1998). The role of self in third-person effects about body image. Journal of Communication, 48(4), pp. 37-58.

Davison, W.P. (1983). The third-person effect in communication. Public Opinion Quarterly, 47, pp. 1-15.

Davison, W.P. (1996). The third-person effect revisited. International Journal of Public Opinion Research, 8, pp. 113-119.

Duck, J.M., Hogg, M.A., Terry, D.J. (1995). Me, us, and them: Political identification and the thirdperson effect in the 1993 Australian federal election. European Journal of Social Psychology, 25, pp. 195-215.

Duck, J.M., Hogg, M.A., Terry, D.J. (1999). Social identity and perceptions of media persuasion: Are we always less influenced than others? Journal of Applied Social Psychology, 29(9), pp. 1879-1899.

Eveland, W.P., Nathanson, A.I., Detenber, B.H., McLeod, D.M. (1999). Rethinking the social distance corollary: Perceived likelihood of exposure and the third-person perception. Communication Research, 26, pp. 275-302.

Golan, G.J. (2002). Religiosity and the third-person effect. Journal of Media and Religion, 1(2), pp. 105-120.

Golan, G.J., Banning, S.A. (2008). Exploring a link between the third-person effect and the theory of reasoned action: Beneficial ads and social expectations. American Behavioural Scientist, 52, pp. 208-224.

Gunther, A.C. (1991). What we think others think: Cause and consequence in the third-person effect. Communication Research, 18, pp. 355-372.

Gunther, A.C. (1995). Overrating the X-rating: The third-person perception and support for censorship of pornography. Journal of Communication, 45(1), pp. 27-38.

Gunther, A.C., Mundy, P. (1993). Biased optimism and the third person effect. Journalism Quarterly, 70, pp. 58-67.

Gunther, A.C., Storey, D. (2003). The influence of presumed influence. Journal of Communication, 53, pp. 199-215.

Hoffner, C., Buchanan, M. (2002). Parents' responses to television violence: The third-person perception, parental mediation, and support for censorship. Media Psychology 4, pp. 231-252.

Huddy, L., Feldman, S., Cassese, E. (2007). On the distinct political effects of anxiety and anger. In: Neuman, W.R., et al. (eds.), The affect effect: Dynamics of emotion in political thinking and behaviour. Chicago, IL: The University of Chicago Press.

Huh, J., Delorme, D.E., Reid, L. (2004). The third-person effect and its influence on behavioural outcomes in a product advertising context: The case of direct-to-consumer prescription drug advertising. Communication Research, 31, pp. 568-599.

Jensen, J., Hurley, R. (2005). Third-person effects and the environment: Social distance, social desirability, and presumed behaviour. Journal of Communication, 55, pp. 242-256.

Kepplinger, H.M. (2008). Effects of the news media on public opinion. In: Donsbach, W., Traugott, M.W. (eds.), The SAGE handbook of public opinion research. Los Angeles, CA: Sage.

Kim, H. (2016). The Role of Emotions and Culture in the Third-Person Effect Process of News Coverage of Election Poll Results. Communication Research. 43(1), pp. 109-130.

Lee, B., Tamborini, R. (2005). Third person effect and Internet pornography: The influence of collectivism and Internet self-efficacy. Journal of Communication, 55, pp. 292-310.

Mangold, W.G., Faulds, D.J. (2009). Social media: the new hybrid element of the promotion mix. Business Horizons, 52(4), pp. 357-365.

McLeod, D.M., Eveland, W.P.Jr, Nathanson, A.I. (1997). Support for censorship of misogynic rap lyrics: An analysis of the third-person effect. Communication Research, 24, pp. 153-174. 
McLeod, D.M., Detenber, B.H., Eveland, W.P. Jr. (2001). Behind the third person effect: Differentiating perceptual processes for self and others. Journal of Communication, 51(4), pp. 678-695.

Meirick, P. (2004). Topic-relevant reference groups and dimensions of distance: Political advertising and first- and third-person effects. Communication Research, 31(2), pp. 234-255.

Meirick, P. (2005). Rethinking the target corollary: The effects of social distance, perceived exposure, and perceived predispositions on first person and third-person perceptions. Communication Research, 32, pp. 822-843.

Nelson, T.E., Clawson, R.A., Oxley, R.A. (1997). Media Framing of a Civil Liberties Conflict and Its Effect on Tolerance. American Political Science Review, 91(3), pp. 567-583.

Neuwirth, K., Frederick, E., Mayo, C. (2002). Person-effects and heuristic-systematic processing. Communication Research, 29, pp. 320-359.

Perloff, R. (1989). Ego-involvement and the third-person effect of televised news coverage. Communication Research, 16, pp. 236-262.

Perloff, R. (1993). Third-person effect research, 1983-1992: A review and synthesis. International Journal of Public Opinion Research, 5, pp. 167-184.

Perloff, R. (1999). The third-person effect: A critical review and synthesis. Media Psychology, 1, pp. 353-378.

Perloff, R. (2002). The third-person effect. In: Bryant, J., Zillmann, D. (eds.), Media effects; advances in theory and research. Mahwah, NJ: Lawrence Erlbaum.

Price, V., Tewksbury, D. (1998). Third-person effects on publication of a Holocaust-denial advertisement. Journal of Communication, 48(2), pp. 3-26.

Price, V., Huang, L.N., Tewksbury, D. (1997). Third-person effects of news coverage: Orientations toward media. Journalism \& Mass Communication Quarterly, 74(3), pp. 525-540.

Reid, S., Hogg, M. (2005). A self-categorization explanation for the third-person effect. Human Communication Research, 31, pp. 129-161.

Rojas, H., Shah, D., Faber, R. (1996). For the good of others: Censorship and the third-person effect. International Journal of Public Opinion Research, 8, pp. 163-186.

Salwen, M.B. (1998). Perceptions of media influence and support for censorship: The third-person effect in the 1996 presidential election. Communication Research, 25, pp. 259-285.

Salwen, M.B., Dupagne, M. (2003). News of Y2K and experiencing Y2K: Exploring the relationship between the third-person effect and optimistic bias. Media Psychology, 5, pp. 57-82.

Schweisberger, V., Billinson, J., Chock, T.M. (2014). Facebook, the Third-Person Effect, and the Differential Impact Hypothesis. Journal of Computer-Mediated Communication, 19, pp. 403-413.

Sun, Y., Pan, Z., Shen, L. (2008). Understanding the third-person perception: Evidence from a metaanalysis. Journal of Communication, 58, pp. 280-300.

Tewksbury, D., Moy, P., Weis, D. (2004). Preparations for Y2K: Revisiting the behavioural component of the third-person effect. Journal of Communication, 54, pp. 138-155.

Tsay-Vogel, M. (2015). Me versus them: Third-person effects among Facebook users. New Media \& Society, 18(9), pp. 1-17.

Tsfati, Y., Cohen, J. (2004). Object-subject distance and the third person perception. Media Psychology, 6, pp. 335-361.

White, H.A. (1997). Considering interacting factors in the third-person effect: Argument strength and social distance. Journalism and Mass Communication Quarterly, 74(3), pp. 557-564.

White, H.A., Dillon, J.F. (2000). Knowledge about others' reaction to a public service announcement: The impact of self-persuasion and third-person perception. Journalism \& Mass Communication Quarterly, 77, pp. 788-803.

Wu, W., Koo, S.H. (2001). Perceived Effects of Sexually Explicit Internet Content: The Third-Person Effect in Singapore. Journalism and Mass Communication Quarterly, 78(2), pp. 260-274.

Zhong, Z. (2009). Third-person perceptions and online games: A comparison of perceived antisocial and prosocial game effects. Journal of Computer-Mediated Communication, 14, pp. 286-306. 